\title{
RADIAL FORCE IMPACT ON THE FRICTION COEFFICIENT AND TEMPERATURE OF A SELF-LUBRICATING PLAIN BEARING
}

\author{
UDC 669.141
}

\author{
Nada Bojić ${ }^{1}$, Dragan Milčić ${ }^{1}$, Milan Banić ${ }^{1}$, Miroslav Mijajlović ${ }^{1}$, \\ Ružica Nikolićc,3 \\ ${ }^{1}$ University of Nis, Faculty of Mechanical Engineering Nis, Serbia \\ ${ }^{2}$ University of Kragujevac, Faculty of Engineering Kragujevac, Serbia \\ ${ }^{3}$ University of Žilina, Research Centre, Slovakia
}

\begin{abstract}
Self-lubricating bearings are available in spherical, plain, flanged journal, and rod end bearing configurations. They were originally developed to eliminate the need for re-lubrication, to provide lower torque and to solve application problems where the conventional metal-to-metal bearings would not perform satisfactorily, for instance, in the presence of high frequency vibrations. Among the dominant tribological parameters of the self-lubricating bearing, two could be singled out: the coefficient of friction and temperature. To determine these parameters, an experimental method was applied in this paper. By using this method, the coefficient of friction and temperature were identified and their correlation was established. The aim of this research was to determine the effect of radial force on tribological parameters in order to predict the behavior of sliding bearings with graphite in real operating conditions.
\end{abstract}

Key Words: Radial Force, Coefficient of Friction, Temperature, Experimental Method

\section{INTRODUCTION}

Self-lubricating sliding bearings possess a number of advantages and they enable significant savings both in maintenance and lubricants. When using bronze bushings with graphite inserts, the graphite forms a thin film on both contact surfaces, which is highly resistant to impacts; besides, it remains in its position even without rotation. Those bushings are used for parts exposed to high loads and low speeds. The most influential

Received August 30, 2016 / Accepted June 02, 2017

Corresponding author: Nada Bojić

University of Nis, Faculty of Mechanical Engineering, Aleksandra Medvedeva 14, 18000 Nis, Serbia

E-mail: nalemfkg@gmail.com 
tribological parameters of self-lubricating sliding bearings with graphite inserts are the material of the sliding pair, radial force, sliding speed, temperature, diameter of graphite inserts, their disposition within the bushing and the percentage coverage of graphite of the overall sliding surface, as well as radial clearance and surface roughness and hardness. As there are many influential parameters, the friction coefficient is usually determined experimentally.

Duriš and Labašová [1] and Labašová [2] experimentally obtained the value of the friction coefficient for the sliding pair aluminum - steel. Their tests were done on Tribotestar M'89. The authors studied the influence of radial load and sliding speed on the value of the friction coefficient. By applying the aforementioned method, Labašová [3, 4] examined the friction coefficient for bronze $(\mathrm{CuZn} 25 \mathrm{Al})$ with inserted lamellar graphite. The results showed that the friction coefficient decreases with an increasing radial load. Although the given research investigated the friction of self-lubricating bearings with inserted lamellar graphite, the values of contact pressure are unknown as the diameter of the joint is not given. Furthermore, the graphite coverage is also unknown as the authors only state that the coverage is between 20 and $30 \%$. The given research was also performed for relatively low values of radial force - up to $600 \mathrm{~N}$.

Ozcarac et al. [5] carried out wear bearing tests on the tribometer with three types of samples. Those were bronzes based on tin and lead - RB-1, RB-7 RB-4. Wear tests were conducted at loads of 10,20 and $40 \mathrm{~N}$ and a sliding speed of $0.5 \mathrm{~m} / \mathrm{s}$ with samples in the form of a ring. Upon the completion of the tests, the weight of samples was measured and the value of the friction coefficient was calculated. Optical and SEM tests were also performed in order to characterize the wear of the above alloys.

Savaskan and Bican [6] tested the friction and wear of the AL-25Zn-3Cu-3 alloy Si on the tribometer by varying the pressure and the sliding speed. They noticed that the friction coefficient of the alloy increases with the sliding speed, but decreases with the increasing pressure up to $1.5 \mathrm{MPa}$; above this pressure value the trend reverses and the friction coefficient increases. However, the temperature and the extent of wear of the alloy increased constantly with the increasing pressure and sliding speed. Pawlak et al. [7] measured, by experimentally establishing the porosity of self-lubricating sliding bearings using the hexagonal boron nitride $(\mathrm{BN}-\mathrm{H})$ as an additive, the friction coefficient of the $(\mathrm{H}-\mathrm{GT}+$ oil $)$ substrate, at varying loads from 1.05 to $2.0 \mathrm{MPa}$ and sliding speeds of 1.35 and $2.5 \mathrm{~m} / \mathrm{s}$. It was found that the addition of oil micro-particles reduces the friction coefficient by about half with respect to the self-lubricating bearings.

Omrani et al. [8] analyzed the tribological properties of Al-16Si-5Ni-5Graphite selflubricating metal matrix composite and compared its tribological properties with steel. They found out that in the case of limited lubrication the Al-16Si-5Ni-5Graphite had values of the friction coefficient lower than steel. Furthermore, the friction coefficient of steel increased with the increase of the applied normal load, while for Al-16Si-5Ni5Graphite it decreased.

The ideal material for sliding bearings would be a material that easily absorbs the abrasive particles and eliminates them if the contact is disturbed. The composite materials possess very good properties in this regard. Suresh et al. [9] researched the composite materials under different loads and sliding speeds by the Pin-on-the tests. Larger wear was recorded with increasing load and sliding speeds. The values of the friction coefficient increased with the subsequent increase of load/sliding speed. It was noticed that the 
graphite, filled by the G-E composite, exhibited a lower friction coefficient than the other two composites, regardless of variations in load/sliding speed.

Liu et al. [10] analyzed the effect of the percentage of graphite in the composite materials by using the UMT - 2MT tribometer. The given research concluded that the appropriate graphite content and hardness of the materials are the two most crucial factors to achieve the desired solid lubrication performance.

The heating of a bearing is usually caused by speed, load and friction within the bearing. In addition to the above parameters, the cooling system failure and external heat sources also cause bearings to heat up. Radila and Zeskotekb [11] measured the temperature of bearing using thermocouples, and came to the conclusion that the greatest impact on temperature increase in a sliding bearing is exerted by an increased number of rpms of the shaft and the radial load.

The objective of investigation by Bonny et al. [12] was to establish the influence of the parameters - the radial forces and the oscillation speed - on the tribological characteristics of the WC-Co cemented carbides during the sliding contact. Prasad [13] recorded a significant increase in wear with increased load.

From the above research, it can be concluded that the mutual relations of the load, the friction coefficient and the quantity of the generated heat are very complex. Although the self-lubricating plain radial bearings with graphite inserts are very widely used, from the above analysis of the previous research one can conclude that there is very little data about their tribological performance in scientific publications. The manufacturers of such bearings claim that, as a rule, the total friction force increases with the load. However, this rule does not apply to the unit friction force and the friction coefficient since they are decreasing. There are two reasons why this happens:

1. The friction coefficient and the specific friction force depend on the real pressure, whose value changes only slightly with increasing load. The friction coefficient decreases with increasing load and thus reduces the tendency of metal to create heat on contact.

2. An increase in the actual contact area is slower than that in the loading. The increased load requires the necessary decrease of clearance because the carrying area of the bearing increases thus lowering the unit pressure.

This paper presents the research on the influence of the radial force value on the friction coefficient and temperature of a self-lubricating plain radial bearing with graphite inserts. Apart from the research by other authors, the effect of radial load was studied with two different values of diameter of graphite inserts, as well as for two values of graphite coverage - 20 and $30 \%$. The values of the radial force were significantly increased in contrast to the above-discussed research of Labašová $[3,4]$.

\section{FRICTION AND TEMPERATURE OF SELF-LUBRICATING BEARINGS}

The coefficient of friction is a complex tribological parameter, which has a stochastic character due to a number of influencing factors. Therefore, the analytical procedure for the determination of the friction coefficient is rather complex. That is further complicated by the character of the contact between a self-lubricating bushing and a shaft, as well as the load of the self-lubricating bushing due to the radial force. Namely, the self-lubricating bushing, through its active surfaces, has a variable contact with the shaft at variable speeds. Therefore, the 
application of an experimental method is a simpler procedure to determine the friction coefficient. The same applies for heat generation as it is a case-sensitive process depending on many parameters that can be estimated only experimentally [14].

To determine the friction coefficient one starts from the Coulomb's equation that relates the load and the friction coefficient in contact of two real bodies as a function of time:

$$
F_{\mu}(t)=\mu(t) \cdot F_{n}(t) \rightarrow \mu(t)=\frac{F_{\mu}(t)}{F_{n}(t)}
$$

where $\mu(t)$ is the friction coefficient, $F_{\mu}(t)$ is the friction force, $F_{n}(t)$ is the normal force and $t$ is the time.

Any increase in friction leads to increased bearing temperature which eventually can cause the destruction of the bearing. The elevated temperature can be a result either of the heat generation or the conditions in which the contact is realized. The increase in temperature, as a result of the heat development caused by friction, is given by:

$$
\Delta T=C \cdot \mu \cdot p \cdot v
$$

where $C$ is the total thermal resistance to the heat dissipation from the surface, $p$ is the contact pressure and $v$ is the sliding speed. The wear intensity depends on pressure $(p)$ and sliding speed $(v)$; thus one takes the value of their product $(p \cdot v)$ of the selected material as a criterion for the design and calculation of the self-lubricating bearing.

Approximate values, recommended in the literature, may range from $0.8 \cdot 10^{-3}$ to $1.8 \cdot 10^{-3}{ }^{\circ} \mathrm{Cms} / \mathrm{N}$ [15]. The friction moment is calculated as:

$$
M_{t r}(t)=F_{n}(t) \cdot L
$$

where $L$ is the lever arm.

In calculating the friction coefficient one starts from Eq. (3). The friction force occurs when there is a relative movement of the shaft with respect to the self-lubricating bearing. It is considered that the friction force is a result of the load (the normal (radial) force) and the torque. The part of the torque that causes the rotation of the shaft, which overcomes the frictional resistance of the contact, is the friction moment, which is a function of time. The friction moment is calculated as the product of the normal force of the sleeve (obtained by the force sensors) and its lever arm. The friction coefficient is calculated by the condition of equality of the friction moment in contact of the bushing and the shaft and the torque by which the entire system acts on the support $\mathrm{O} 2$.

\section{EXPERIMENT}

Experimental research of the self-lubricating bearings was conducted in order to determine the friction coefficient and temperature. Figure 1 shows the configuration for measuring the variables necessary to determine the friction coefficient at the contact of the self-lubricating bearing and the shaft. The main rotational motion, provided by a working machine - lathe (LT), was transferred to driving shaft (DS) by torque sensor (M1) and clutch (C1). Self-lubricating bearing (SB) was mounted on the shaft sleeve. The 
bearing was radially and axially fixed by the upper (US) and the lower (LS) part of the support. Through the opening of upper support (US), by the lower addition of force sensor (AS), the radial force, induced by tightening the screw, acted on the bearing, while the magnitude of the force was measured by force sensor (M2). The circumferential force, which represents the frictional force of the bearing, was measured by lever (L1), of length $150 \mathrm{~mm}$, which was placed perpendicular to the axis of the bearing and rigidly mounted on upper support (US). Sensor (S1) measured the intensity of this force. The temperature of the self-lubricating bearing was measured by thermocouples $\mathrm{T}(t)$ and $\mathrm{T} 1(t)$, where thermocouple $\mathrm{T}(t)$ measured the temperature at the center of the bearing bushing, while thermocouple $\mathrm{T} 1(t)$ measured the temperature at the end of bearing bushing (SB). Thermal camera $(\mathrm{T})$ recorded the temperature of the end surface of the bearing frontal bed. All the sensors, thermocouples were connected to computer unit (R), which performed the data acquisition. The images from the thermal camera were taken immediately when the lathe stopped, i.e. at the stopping of the shaft rotation.

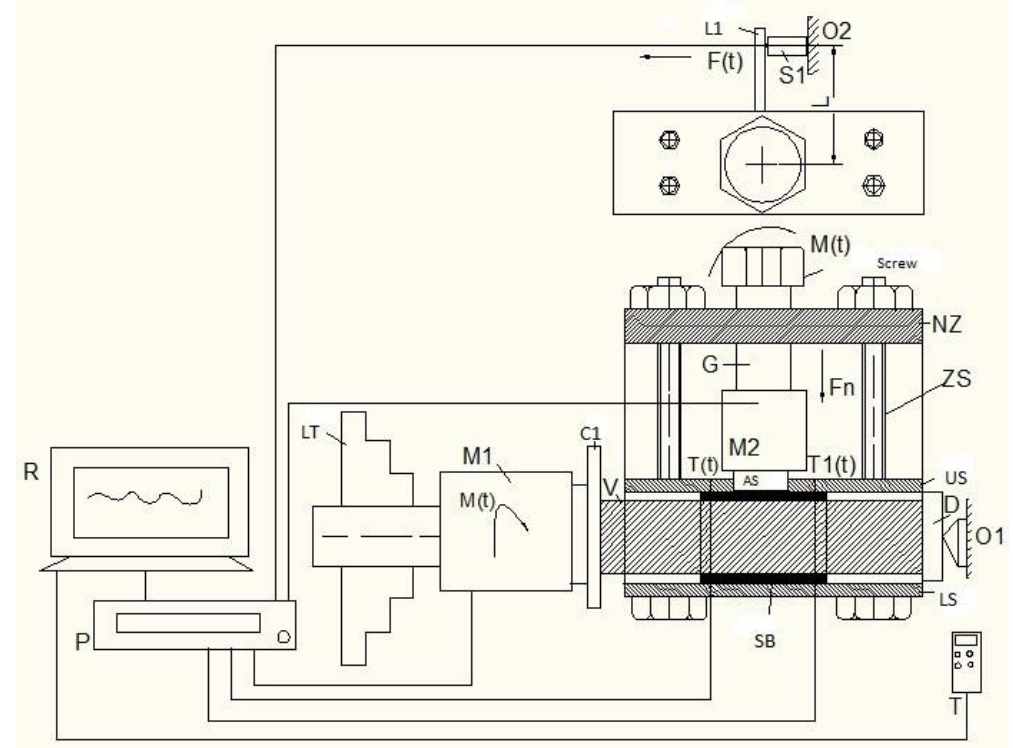

Fig. 1 The scheme of the measurement configuration

The lathe "Potisje Ada PA-C30" was used for testing the self-lubricating bearing, as well as the measuring system, which consisted of a measuring and amplifier device "National Instruments cDAQ-9178", torque sensor "Hottinger Baldwin Messtechnik T1" (100 Nm), force sensors "Hottinger Baldwin Messtechnik S7M" (500 N) and "Hottinger Baldwin Messtechnik U9" (5 kN), two K-type thermocouples and thermal imaging camera FLIR E 50.

The self-lubricating plain bearings with graphite, 50/40x40, were used in this experiment, manufactured by Fasil a.d., whose beds were made of substrate high quality bronze CuSn12 with inserts (lamellae) of graphite of diameter of 8 and $10 \mathrm{~mm}$, which homogeneously adhered to the two surfaces occupying $20 \%$ or $30 \%$ of the casings. In total 4 bushings 
were tested each with a unique combination of graphite inset diameter and graphite coverage. Fig. 2 shows the technical drawing of the self-lubricating bearing with the diameter of inserts of $10 \mathrm{~mm}$ and graphite coverage of $20 \%$.

During the tests the ambient temperature value was $25{ }^{\circ} \mathrm{C}$ and all the tests were performed with the rotation speed of $54 \mathrm{rpm}$ which corresponded to sliding speed of $0,113 \mathrm{~m} / \mathrm{s}$. Tolerances of all the bushings were checked before the experiment. The experimental testing was performed with two values of radial force -1500 and $3000 \mathrm{~N}$. The time of experiment was 1200s for every bushing and the measurements were performed five consecutive times on every individual bushing. The bushings were initially rotated for 10 min before the test with graphite polishing grease NLGI class 2 . When this run was completed, the bushings were cleaned from the grease before the actual tests.

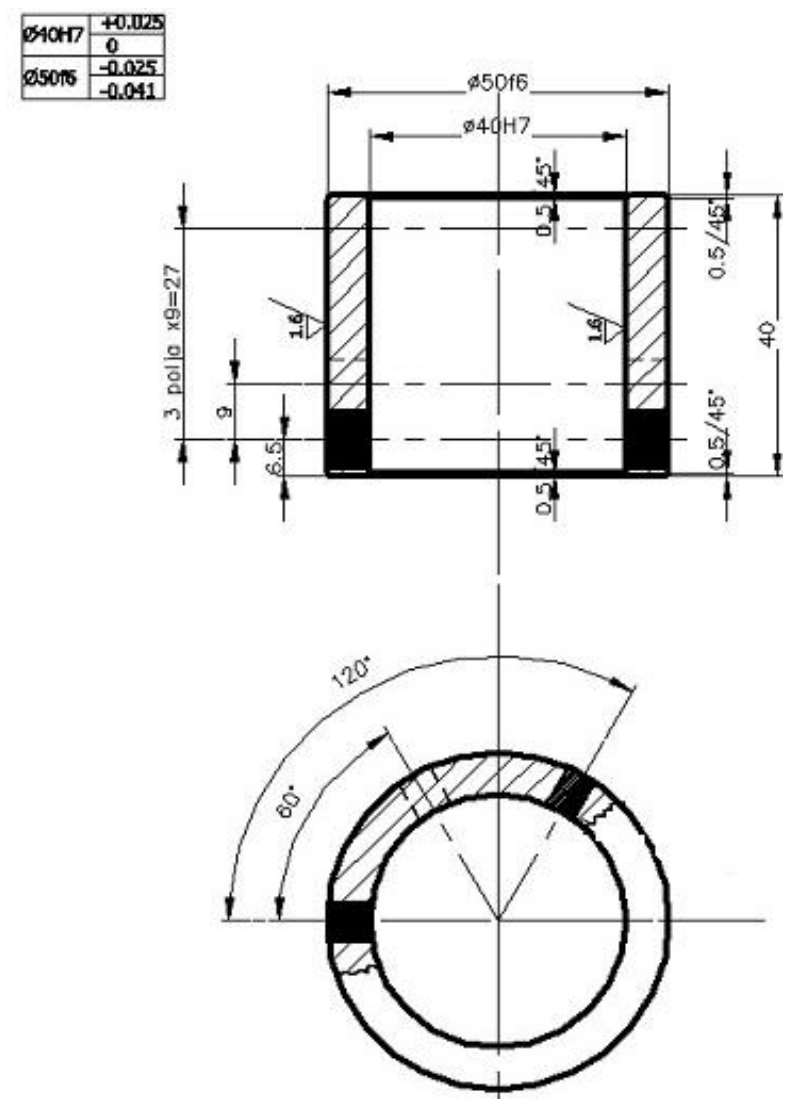

Fig. 2 The self-lubricating bearing $\varnothing 50 / 40 x 40$, with inserts (lamellae) of graphite of a diameter of $10 \mathrm{~mm}$, coverage of $20 \%$ 


\section{RESULTS AND DISCUSSION}

The following notation was used during the experiment: aa_bb_cc_dddd, where the first group of symbols (aa) designate the diameter of the graphite inserts, the second (bb) the percent of graphite coverage, the third (cc) sliding speed and the fourth (dddd) the value of the radial force.

Table 1 summarizes the results of the experiments for 4 tested samples at two values of radial force. The results presented in Table 1 provided the data for the last test, as there were 5 tests per bushing in order to secure the repeatability of results. The results were monitored during all 5 tests in order to avoid possible experimental mistakes. The temperature value in Table 1 was given at the end of the test, i.e after all 5 consecutive tests on an individual bushing with distinctive insert diameters and graphite coverages. It was observed during the experiments that, after 2 to 3 consecutive tests on an individual bushing, a thermal equilibrium was achieved, so there was no increase in the temperature of the bushing in the fourth and fifth tests.

Table 1 Experimental results

\begin{tabular}{lccc}
\hline Bushing & $\begin{array}{c}\text { Real value } \\
\text { of radial force, } \mathrm{N}\end{array}$ & Friction coefficient & Temperature, ${ }^{\circ} \mathrm{C}$ \\
\hline 8_20_54_1500 & 1394.5 & 0.079 & 43 \\
8_30_54_1500 & 1428.8 & 0.077 & 53 \\
10_20_54_1500 & 1500.8 & 0.039 & 33.5 \\
10_30_54_1500 & 1475.8 & 0.041 & 37 \\
8_20_54_3000 & 2967 & 0.09 & 54.8 \\
8_30_54_3000 & 3049.4 & 0.09 & 51.1 \\
10_20_54_3000 & 2772.3 & 0.055 & 43.7 \\
10_30_54_3000 & 2917.7 & 0.044 & 41.50 \\
\hline
\end{tabular}

As the radial force is supplied by tightening of the screw there was a small variation in the obtained radial force from the desired values (1500 and $3000 \mathrm{~N}$ ). Furthermore, due to thermal expansion of the bushing the value of the radial force for each individual bushing was readjusted between the consecutive runs regardless of the fact that thermal equilibrium was obtained in the fifth run.

Figure 3 shows the value of radial force (a), friction coefficient (b), temperature measured by the thermocouple on the bushing frontal bed (c) and thermal image of the bushing frontal bed (d). The variation of the result for the friction coefficient in Fig. 3b is a result of the lathe induced vibrations. However, as clearly shown in the figure, the average value of friction coefficient is $\mu=0.039$. The small oscillations of radial force value are also a consequence of the lathe induced vibration with average value of $F_{r}=1500.8 \mathrm{~N}$. From the figure it is also clear that there is a good agreement between the thermocouple and thermographic measurements. 

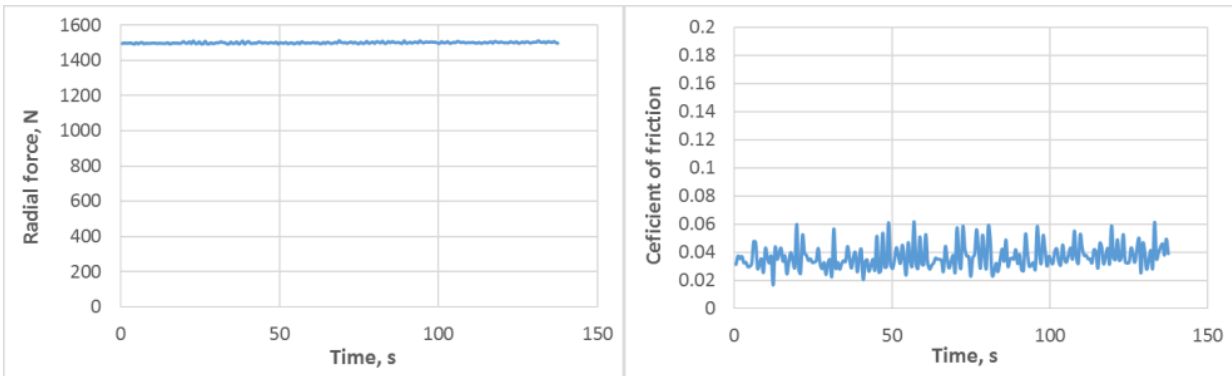

a)

b)

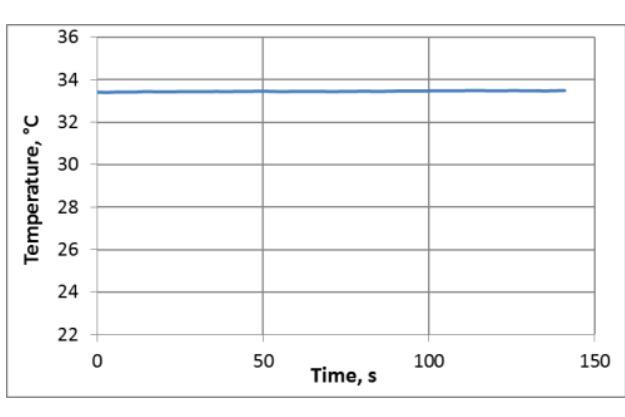

c)

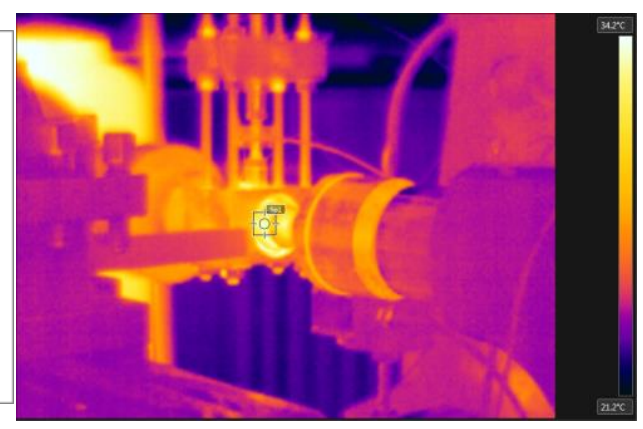

d)

Fig. 3 Results of experimental measurements for a bushing 10_20_54_1500: a) radial force (average value $F_{r}=1500.8 \mathrm{~N}$ ), b) friction coefficient (average value $\mu=0.039$ ), c) temperature measured by thermocouple (average value $T=33.49^{\circ} \mathrm{C}$ ), d) temperature measured by the thermal imaging camera of $33.5^{\circ} \mathrm{C}$ at bushing frontal bed

Figure 4 shows the influence of radial force on the value of the friction coefficient for different diameters of graphite inserts and different graphite coverages. In contrast to the findings of the other authors and the data provided by the manufacturers of such bearings, as clearly shown in the figure, the coefficient of friction increases with an increase in radial load for values of contact pressure greater than approximately $0.95 \mathrm{MPa}$ (radial load of $1500 \mathrm{~N}$, bushing diameter $\mathrm{x}$ width - $40 \mathrm{x} 40 \mathrm{~mm}$ ). The lowest values of the friction coefficient were obtained for $10 \mathrm{~mm}$ inserts and radial force value of $1500 \mathrm{~N}$. Obviously, the larger contact area of an individual graphite insert helps the better distribution of solid lubricant inside the bushing. It is also clear that the graphite coverage does not have a significant influence on a lower value of radial force $(1500 \mathrm{~N})$. The situation changes with the increase in the load. For instance, with $10 \mathrm{~mm}$ inserts and coverage of $20 \%$ there is a greatest increase in the friction coefficient value with an increase in radial load, while for $30 \%$ coverage there is almost no rise of the friction coefficient value. The increase of friction coefficient value is probably a consequence of plastic saturation of the contact. Plastic saturation of a contact occurs when all (or almost all) asperities are in contact. In such circumstances the molecular component of the friction coefficient is independent of contour pressure, while the deformational component intensively increases with an increase 
in contour pressure [16]. These findings should be further investigated in order to determine the exact reasons for the increase in the friction coefficient with radial load and mechanisms behind it.

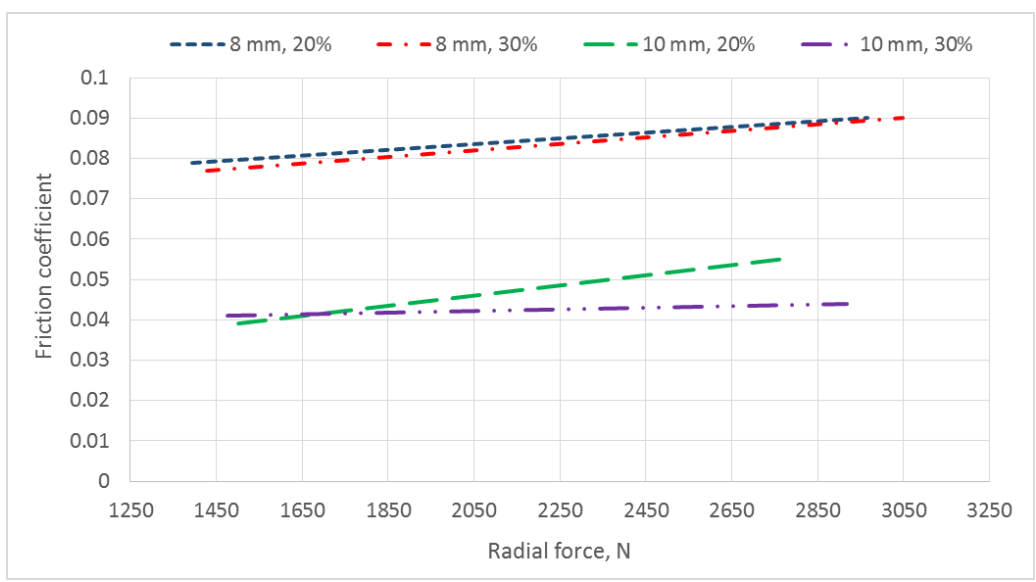

Fig. 4 The influence of radial force on the friction coefficient for various graphite insert diameters and graphite coverage

Figure 5 shows the influence of radial force on the value of temperature of the selflubrication plain bearing with graphite inserts for different diameters of graphite inserts and different graphite coverages.

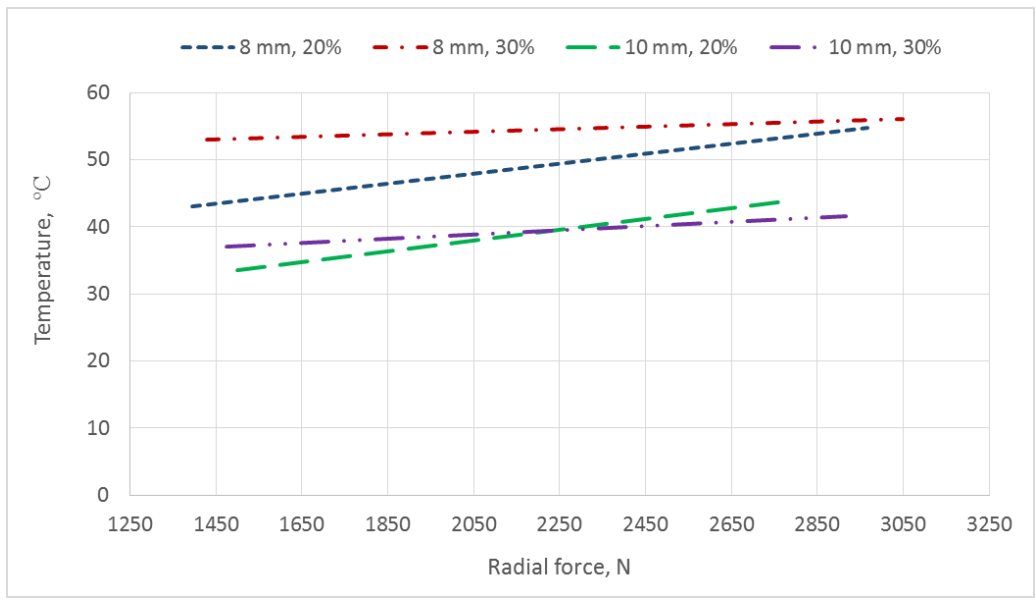

Fig. 5 The influence of radial force on the temperature for various graphite insert diameters and graphite coverages

As in the case of the coefficient of friction, there is an increase in temperature with the increase in the load. The increase is more pronounced for the bushings with lower value 
of graphite coverage. The results are expected as any increase in the friction coefficient leads to an increase in temperature. Furthermore, the obtained temperatures are within the permissible limits as they are below $100{ }^{\circ} \mathrm{C}$, which is a limiting temperature for this type of bearings. As graphite has a near zero coefficient of thermal expansion, it will not expand with the increase in temperature as the bronze sleeve will. If the temperature is greater than the limiting temperature, the graphite inserts will become loose, which leads to lower lubrication and destruction of the bearing due to wear and scuffing.

\section{CONCLUSIONS}

This paper presents the experimental research into the influence of radial load on the coefficient of friction and temperature of self-lubricating plain radial bearings with graphite inserts. The effect of radial load was determined for two different values of graphite inserts, as well as for two values of graphite coverage.

It is determined that the friction coefficient value increases with the increase in radial load probably due to plastic saturation of the contact at a nominal contact pressure greater than $1 \mathrm{MPa}$. Mechanisms which lead to such behavior should be further investigated. The increase of diameter of graphite inserts from 8 to $10 \mathrm{~mm}$ leads to lower values of the coefficient of friction. The percent of graphite coverage does not influence the value of the friction coefficient significantly for the contact pressure of $1 \mathrm{MPa}$. With the increase in contact pressure, the influence of graphite coverage becomes more pronounced.

The temperature of a self-lubricating plain radial bearing with graphite inserts in the given geometric configuration increases with the increase in radial load. Such behavior is expected, as an increase in the friction coefficient is followed by an increase in temperature.

As already noted, further research should be directed towards understanding the friction mechanisms above the contact pressure of $1 \mathrm{MPa}$, as well as the combined influence of radial load and sliding speed.

\section{REFERENCES}

1. Duriš, R., Labašová E., 2013, Experimental Determination of the Coefficient of Friction in Rotational Sliding Joint, Applied Mechanics and Materials, 309, pp. 50-54.

2. Labašová, E., 2014, The Dependence of the Friction Coefficient on the Size and Course of Sliding Speed, Applied Mechanics and Materials, 693, pp. 305-310.

3. Labašová, E., 2014, The Size of the Friction Coefficient Depending on the Size and Course of Normal Load, Applied Mechanics and Materials, 474, pp. 303-308.

4. Labašová, E., 2012, Measurement of the Tribology Characteristics in Sliding Joint, American International Journal of Contemporary Research, 2, pp. 304-309.

5. Ozsarac, U., Findik, F., Durman, M., 2007, The wear behaviour investigation of sliding bearings with a designed testing machine, Materials \& Design, 28, pp. 345-350.

6. Savaşkan, T., Bican, O., 2010, Dry sliding friction and wear properties of Al-25Zn-3Cu-3Si alloy, Tribology International, 43(8), pp. 1346-1352.

7. Pawlak, Z., Kaldonski, T., Pai, R., Bayraktar, E., Oloyede, A., 2009, A comparative study on the tribological behaviour of hexagonal boron nitride $(h-B N)$ as lubricating micro-particles-An additive in porous sliding bearings for a car clutch, Wear, 267, pp. 1198-1202.

8. Omrani, E., Moghadam, A. D., Algazzar, M., Menezes P. L., Rohatgi, P. K., 2016, Effect of graphite particles on improving tribological properties Al-16Si-5Ni-5Graphite self-lubricating composite under fully flooded and starved lubrication conditions for transportation applications, The International Journal of Advanced Manufacturing Technology, 87(1), pp. 929-939. 
9. Suresha, B., Chandramohan G., Prakash J. N., Balusamy V., Sankaranarayanasamy K., 2006, The Role of Fillers on Friction and Slide Wear Characteristics in Glass-Epoxy Composite Systems, Journal of Minerals and Materials Characterization and Engineering, 5, pp. 87-101.

10. Liu, R. T., Xiong, X., Chen, F. C., Lu, J. Z., Hong, L. L., Zhang Y.-Q., 2011, Tribological performance of graphite containing tin lead bronze-steel bimetal under reciprocal sliding test, Tribology International, 44, pp. 101-105.

11. Radila, K., Zeszotekb M., 2004, An Experimental Investigation into the Temperature Profile of a Compliant Foil Air Bearing, Tribology Transactions, 47, pp. 470-479.

12. Bonny, K., Baets P. De, Perez Y., Vleugels J., Lauwers, B., 2010, Friction and wear characteristics of WC-Co cemented carbides in dry reciprocating sliding contact, Wear, 268(11-12), pp. 1504-1517.

13. Prasad, B. K., 2011, Sliding wear response of a grey cast iron: Effects of some experimental parameters, Tribology International, 44(5), pp. 660-667.

14. Mijajlović, M., 2013, Numerical simulation of the material flow influence upon heat generation during friction stir welding, Facta Universitatis series Mechanical Engineering, 11(1), pp. 19-28.

15. Heise, R., 2015, Flash temperatures generated by friction of a viscoelastic body, Facta Universitatis series Mechanical Engineering, 13(1), pp. 47-65.

16. Stamenković, D., Milošević, M., Mijajlović, M., Banić, M., 2012, Recommendations for the estimation of the strength of the railway wheel set press fit joint, Proceedings of the Institution of Mechanical Engineers, Part F: Journal of Rail and Rapid Transit, 226(1), pp. 48-61. 